\title{
Catastrophizers with chronic pain display more pain behaviour when in a relationship with a low catastrophizing spouse
}

\author{
Nathalie Gauthier MPs ${ }^{1}$, Pascal Thibault $\mathrm{PhD}^{2}$, Michael JL Sullivan $\mathrm{PhD}^{2}$
}

\begin{abstract}
N Gauthier, P Thibault, MJL Sullivan. Catastrophizers with chronic pain display more pain behaviour when in a relationship with a low catastrophizing spouse. Pain Res Manage 2011;16(5):293299.

The present study examined the relationship between couple concordance of catastrophizing and adverse pain outcomes. Possible mechanisms underlying the relationship between couple concordance of catastrophizing and pain outcomes were also explored. Fifty-eight couples were recruited for the study. The chronic pain patients were filmed while lifting a series of weighted canisters. The spouse was later invited to view the video and answer questions about the pain experience of their partner. Median splits on Pain Catastrophizing Scale scores were used to create four 'catastrophizing concordance' groups: low catastrophizing patient-low catastrophizing spouse; low catastrophizing patient-high catastrophizing spouse; high catastrophizing patient-low catastrophizing spouse; and high catastrophizing patient-high catastrophizing spouse. Analyses revealed that high catastrophizing pain patients who were in a relationship with a low catastrophizing spouse displayed more pain behaviours than patients in all other groups. These findings suggest that high catastrophizing chronic pain patients may need to increase the "volume' of pain communication to compensate for low catastrophizing spouses' tendency to underestimate the severity of their pain experience. Patients' perceived solicitousness and punitive response from the spouse could not explain the group differences in pain behaviour. Theoretical and clinical implications of the findings are discussed.
\end{abstract}

Key Words: Catastrophizing; Communal coping model; Couple concordance; Pain behaviours; Pain communication; Persistent pain

In recent years, there has been increased interest in examining interpersonal and relational aspects of pain. Spouse or partner characteristics, such as distress, solicitousness, support and level of catastrophizing, have been shown to be associated with pain patients' level of pain and emotional distress $(1,2)$. The present study addressed the relationship between patient and spouse concordance of catastrophizing and pain outcomes.

Numerous investigations have shown that high levels of pain catastrophizing by pain patients are associated with heightened pain, emotional distress, pain behaviour and pain-related disability (3). According to the communal coping model of pain catastrophizing (4), the pain expressions of high catastrophizers serve a social communicative function aimed at maximizing the probability that distress will be managed within a social/interpersonal context. Sullivan et al (3) suggested that high catastrophizers may engage in exaggerated pain expression to maximize proximity, or to solicit assistance or empathic responses from others. Catastrophizers' expressive pain displays may also be used to induce others to alter their expectations, reduce performance demands or manage interpersonal conflicts.

Communication models of pain $(5,6)$ propose that pain communication is a joint function of characteristics of the sender and the receiver.
Les catastrophistes souffrant de douleurs chroniques affichent plus de comportements de douleur lorsque leur conjoint catastrophise peu

La présente étude portait sur la relation entre la concordance de catastrophisation du couple et les issues indésirables de la douleur. Les chercheurs ont également exploré les mécanismes susceptibles d'être sous-jacents à la relation entre la concordance du couple à la catastrophisation et les issues de la douleur. Cinquante-huit couples ont été recrutés pour l'étude. Les patients atteints de douleur chronique ont été filmés pendant qu'ils soulevaient des contenants lestés. Le conjoint a ensuite été invité à regarder la vidéo et à répondre à des questions sur la douleur que ressentait leur partenaire. Les chercheurs ont utilisé la division médiane des indices de l'échelle de catastrophisation de la douleur pour créer quatre groupes de « concordance de catastrophisation » : les patients catastrophisant peu dont le conjoint catastrophisait peu, les patients catastrophisant peu dont le conjoint catastrophisait beaucoup; les patients catastrophisant beaucoup dont le conjoint catastrophisait peu et les patients catastrophisant beaucoup dont le conjoint catastrophisait beaucoup. Les analyses ont révélé que les patients qui catastrophisent beaucoup leur douleur et dont le conjoint catastrophise peu affichaient plus de comportements de douleur que ceux de tous les autres groupes. Les présentes observations indiquent que les patients souffrant de douleurs chroniques qui catastrophisent beaucoup peuvent avoir besoin d'accroître le « volume » de communication de leur douleur pour compenser la tendance du conjoint qui catastrophise peu à sous-estimer la gravité de la douleur qu'ils ressentent. La sollicitude perçue par les patients et la réponse punitive du conjoint ne pouvaient pas expliquer les différences de comportements liés à la douleur entre les groupes. Les répercussions théoriques et cliniques de ces observations sont exposées.

Senders may vary in their ability to effectively communicate pain, and receivers may vary in their ability to accurately interpret the pain communications they receive. To date, research has shown that high pain catastrophizers display more pain behaviour than low pain catastrophizers (7-10), and are more effective than low catastrophizers in accurately communicating their pain (8). Research has also shown that the level of catastrophizing of the observer influences how pain behaviours are interpreted (11). Specifically, low catastrophizers appear to be particularly prone to underestimating others' pain $(11,12)$.

Proceeding from a communication perspective on pain catastrophizing, it could be predicted that the highest levels of physical and emotional distress would be seen in couples for whom the pain patient is a high catastrophizer and the spouse is a low catastrophizer. Under these conditions, the high catastrophizing pain patient may need to increase the 'volume' of pain communication to compensate for the low catastrophizing spouses' tendency to underestimate pain signals.

In contrast to a communication perspective on pain catastrophizing, cognitive-behavioural models suggest that pain catastrophizing represents an appraisal process that is characterized by alarmist interpretations of pain or other health threats $(13-16)$. High threat appraisals are expected to contribute to increased physical and emotional

${ }^{1}$ Department of Psychology, Université de Montréal; ${ }^{2}$ Department of Psychology, McGill University, Montréal, Québec

Correspondence: Dr Michael JL Sullivan, Department of Psychology, McGill University, 1205 Docteur Penfield, Montréal, Québec H3A 1 B1 .

Telephone 514-398-5677, e-mail michael.sullivan@mcgill.ca 
distress. From a cognitive-behavioural perspective, it could be predicted that adverse pain outcomes would be most pronounced in couples for whom both the pain patient and the spouse are high pain catastrophizers. It is possible that through the course of the relationship, high catastrophizing spouses may be more likely than low catastrophizing spouses to reinforce or model alarmist interpretations of pain. Over time, the threat appraisals of both high catastrophizing partners may have a summative effect, contributing to heightened distress and pain, and in turn, to heightened pain behaviour and disability.

A greater understanding of partner influences on pain patients' health and mental health outcomes has both clinical and theoretical implications. Research examining the interactive nature of pain communication will contribute to the refinement of conceptual models of social contextual influences on pain outcomes, and may have clinical implications for the assessment and treatment of persistent pain conditions.

The primary purpose of the present study was to investigate the relationship between couple concordance of catastrophizing and pain outcomes. Patients experiencing chronic pain were filmed while lifting a series of weighted canisters. Analyses addressed whether the patients' level of catastrophizing interacted with the spouses' level of catastrophizing in determining pain severity, pain behaviour displays, depression and pain-related disability. Possible mechanisms underlying the relationship between couple concordance of catastrophizing and pain outcomes were also explored. Specifically, the pain patients' perceptions of solicitous and punitive responses from the spouse were examined as possible reinforcing or punishing factors that could explain variations in pain outcomes.

\section{METHODS}

\section{Participants}

The study sample consisted of 58 individuals (30 men and 28 women) suffering from persistent neck or back pain, and their spouses. Participants were recruited through advertisements placed in newspapers in Montreal, Quebec. Eligible participants were individuals between 20 and 55 years of age, who had been experiencing back or neck pain for more than six months and were currently in a relationship (married or common law). All participants were examined by a physician or an occupational therapist to identify and exclude participants with a medical condition that could be adversely affected by the lifting task. The mean age of the pain patients was 40.0 years (range 20 to 58 years). The mean duration of pain was 8.0 years (range one to 30 years). The most commonly reported primary pain site was the back $(90 \%)$. The sample included English- and French-speaking participants.

\section{Procedure}

All procedures were approved by the research ethics board of the Centre for Interdisciplinary Research in Rehabilitation of Greater Montreal. On patients' arrival at the laboratory, a research assistant informed the pain patients and their spouses that the study focused on the impact of persistent pain on couple relationships. Informed consent was obtained from patients and their spouses. Pain patients completed the McGill Pain Questionnaire (MPQ [17,18]), the Beck Depression Inventory-II (BDI-II [19]), the Pain Disability Index (PDI $[20,21])$, the Pain Catastrophizing Scale (PCS [22,23]) and the Multidimensional Pain Inventory-Patient Version (MPI [24,25]). Spouses completed the BDI-II (19) and the PCS (for their own catastrophizing level) $(22,23)$.

Pain patients completed a simulated occupational lifting task modelled after Butler and Kozey's model (26), while their spouses sat in a waiting room out of sight of the laboratory. Patients were asked to stand behind a waist-level table with 18 canisters partially filled with sand, weighing $2.9 \mathrm{~kg}, 3.4 \mathrm{~kg}$ and $3.9 \mathrm{~kg}$. The canisters were placed in three rows of six columns, with the different weights and positions arranged according to a double Latin square. The selection of loads was based on research suggesting a $12 \%$ weight difference for detection threshold and the National Institute for Occupational Safety and Health's recommendations for safety weight limits $(27,28)$.
The patients lifted each canister under two instructional sets: weight estimation and pain rating. For the weight estimation task, patients lifted the canisters in a predetermined order and estimated the weight of each canister. For the pain rating task, patients lifted each canister in the same order and rated their pain on a scale from 0 (no pain) to 10 (extreme pain). The weight estimation and pain rating tasks were counterbalanced across patients.

The canister locations required the adoption of three different functional anthropometric postural positions: normal, maximum and extreme reaches. For canisters in the first row (ie, closest to the body), participants stood erect with the elbow of their dominant arm bent at 90 degrees (Position 1); for canisters in the second row, participants stood erect with their dominant arm fully extended (Position 2); and for canisters in the third row, the participant's trunk was forward flexed with his/her dominant arm fully extended (Position 3). The task was designed such that the trunk forward flexion and arm extension required to lift canisters farther away from the body would engage the musculature of the upper limbs, cervical and lumbar spine.

A research assistant was present in the laboratory to record the responses (ie, weight estimates and pain ratings) of the patient. The patient was informed that the lifting task was being video recorded, and that the spouse would later be invited to view the video and respond to questions about his/her pain experience.

\section{Measures}

Catastrophizing: The PCS $(22,23)$ was used as a measure of catastrophic thinking related to pain. The PCS consists of 13 items describing different thoughts and feelings related to pain. For each item, respondents rate the frequency at which they experience each thought or feeling on a five-point scale with end points of 0 (not at all) and 4 (all the time). The scores on the PCS range from 0 to 52. Numerous investigations have supported the reliability and the validity of the PCS as a measure of pain-related catastrophic thinking $(4,23,29,30)$.

Pain severity: The MPQ $(17,18)$ was used as an index of pain severity. The Pain Rating Index (PRI) of the MPQ is derived as the weighted sum of values corresponding to pain adjectives endorsed by the respondent to describe his/her pain. MPQ PRI scores range from 0 to 78. The MPQ PRI is considered to be a reliable and valid index of an individual's chronic pain experience (31). Patients also rated their present pain intensity on an 11-point scale with the end points 0 (no pain) and 10 (extreme pain).

Depression: The BDI-II is a widely used self-report measure of depression composed of 21 items describing symptoms of depression (19). Respondents are asked to endorse statements that best describe how they have been feeling during the past two weeks. The BDI-II has been shown to be a reliable (coefficient $\alpha=0.84$ ) and valid index of depressive symptoms experienced by persistent pain patients and primary care medical patients (32-34).

Disability: The PDI $(20,21)$ was used as a self-report measure of functional disability. On this scale, respondents are asked to rate their level of disability in seven different areas of daily living (home, social, recreational, occupational, sexual, self-care and life support) (35). For each life domain, respondents provide disability ratings on 11-point scales with end points of 0 (no disability) and 10 (total disability). The PDI has been shown to be internally reliable and significantly correlated with objective indexes of disability $(21,36)$.

Patients' perception of spouse responses to pain: The MPI $(24,25)$ is a 52 -item inventory designed to assess psychosocial components of chronic pain experience. The MPI was used to measure patients' perception of spouse punishing (four items), solicitous (six items) and distracting (four items) responses to pain on a seven-point Likert scale ranging from 0 (never) to 6 (very often). The MPI has been shown to have good construct and discriminant validity, internal consistency and test-retest reliability $(24,25)$.

Spouses' pain estimates: Spouses were asked to view the video (without audio) of the pain rating task that was completed by their partner and to estimate, for each canister lifted, the level of pain of their 
partner on a scale from 0 (no pain) to 10 (extreme pain). Spouse's pain estimates were averaged across the 18 canisters so that the variable ranged from 0 (no pain) to 10 (extreme pain).

Pain behaviours: Two judges who were blinded to experimental hypotheses and trained in a pain behaviour coding procedure described by Sullivan et al (37), independently coded each video for the presence of communicative and protective pain behaviours. Communicative pain behaviours included facial expressions such as grimacing or wincing, and verbal or paraverbal pain expressions such as pain words, grunts, sighs and moans. Protective pain behaviours included movements such as guarding, holding, touching or rubbing.

For each canister, the duration of communicative and protective pain behaviours was recorded. For facial expressions, judges rated the intensity of each facial expression as either mild, moderate or intense. Composite indexes of facial expressions were computed by multiplying the duration of pain behaviour by its intensity and summing across all 18 canister lifts (38). Intensity was not rated for protective pain behaviours because previous research from the laboratory revealed that behaviours such as rubbing, holding, touching or guarding are not readily characterized in terms of intensity. Therefore, only duration was recorded for protective pain behaviours. The mean correlation between judges' coding for the duration of each category of pain behaviour was 0.86 . For the duration of pain behaviour, the scores of the two judges were averaged. The mean percentage agreement for the classification of each category of pain behaviour was $86 \%$. Discrepancies were resolved through discussion. For the purpose of the present article, a composite pain behaviour score was derived as the sum of all the pain behaviours across the two tasks.

Data analysis approach: Patients and spouses were classified as high catastrophizers or low catastrophizers based on a median split (median $=24)$ of their scores on the PCS $(22,23)$. Thus, four 'catastrophizing concordance' groups were created: low catastrophizing patient-low catastrophizing spouse; low catastrophizing patient-high catastrophizing spouse; high catastrophizing patient-low catastrophizing spouse; and high catastrophizing patient-high catastrophizing spouse.

ANOVA with repeated measures were used to assess the effects of patient and spouse's catastrophizing levels, canister weight and canister position on pain ratings, pain behaviours, depression, disability and spouses' pain estimates. Initial analyses revealed that lighter canisters elicited a low frequency of pain behaviours such that several cells in the design contained only null values. Therefore, pain behaviours were summed across different weight canisters, removing canister weight as a factor in the analyses of pain behaviours. Because there was no significant effect involving sex for variables of interest, this variable was dropped from further analysis.

Before analysis, scores of pain behaviours, pain ratings and patient PCS scores were examined for multivariate outliers. By using Mahalanobis distance squared with $\mathrm{P}<0.05$, eight participants were identified as multivariate outliers and excluded from further analysis, thus reducing the sample size to 50 couples.

Examination of the normality of the different variables revealed that the distribution of the total amount of pain behaviours was positively skewed. Therefore, a square root transformation on the total amount of pain behaviour was performed, and all analyses used the square rooted variable (39). Transformed variables do not represent a real unitary value of the original variable. However, the relationships between transformed variables and other (untransformed) variables are not affected. Although analyses were conducted on the square root transformation of the pain behaviour variables, the untransformed means and SDs are presented in the tables and figures.

\section{RESULTS}

\section{Sample characteristics}

Table 1 presents the means and SDs for patients' and spouses' demographics. Scores on measures of pain severity, catastrophic thinking, self-reported disability and depression were comparable with those that have been reported in previous research (40).
TABLE 1

Sample characteristics: Pain patients and their spouses

\begin{tabular}{lccc}
\hline & \multicolumn{2}{c}{ Pain patients } & \\
\cline { 2 - 3 } & Men $\mathbf{( n = 2 6 )}$ & Women $\mathbf{( n = 2 4 )}$ & $\mathbf{P}$ \\
\hline Age, years & $40.8 \pm 8.0$ & $39.4 \pm 10.6$ & 0.59 \\
Pain duration, years & $6.9 \pm 9.9$ & $8.5 \pm 6.4$ & 0.35 \\
Relationship duration, years & $10.04 \pm 7.3$ & $12.3 \pm 11.7$ & 0.41 \\
Mean pain during the lifting task & $3.3 \pm 2.1$ & $4.4 \pm 2.7$ & 0.09 \\
MPQ-PPI & $4.9 \pm 2.0$ & $4.1 \pm 2.4$ & 0.20 \\
MPQ-PRI & $23.0 \pm 13.1$ & $29.0 \pm 16.6$ & 0.16 \\
MPQ-number of pain sites & $1.8 \pm 1.0$ & $2.2 \pm 1.0$ & 0.21 \\
PDI & $21.3 \pm 12.0$ & $30.0 \pm 15.4$ & 0.24 \\
BDI-II & $12.9 \pm 8.1$ & $15.5 \pm 10.9$ & 0.34 \\
PCS & $23.7 \pm 9.4$ & $27.1 \pm 13.1$ & 0.30 \\
& \multicolumn{2}{c}{ Spouses } & \\
\cline { 2 - 3 } & Men $(\mathbf{n}=\mathbf{2 5})$ & Women $(\mathbf{n}=\mathbf{2 5})$ & $\mathbf{P}$ \\
\hline Age, years & $43.4 \pm 11.4$ & $36.6 \pm 11.1$ & 0.04 \\
BDI-II & $8.9 \pm 8.3$ & $11.4 \pm 8.6$ & 0.30 \\
PCS & $28.0 \pm 13.0$ & $22.8 \pm 9.0$ & 0.95 \\
Mean perceived pain during the & $4.1 \pm 2.1$ & $2.6 \pm 2.0$ & 0.01 \\
lifting task & & & \\
\hline
\end{tabular}

Data presented as mean \pm SD. BDI-II Beck Depression Inventory-II; MPQ McGill Pain Questionnaire; PCS Pain Catastrophizing Scale; PDI Pain Disability Index; PPI Present Pain Intensity; PRI Pain Rating Index

Table 2 presents correlations between all pain-related variables and patients' pain behaviours. Consistent with previous research, catastrophizing (PCS), fear of movement/re-injury (Tampa Scale for Kinesiophobia) and self-reported disability were significantly correlated with pain behaviour $(9,37)$.

Table 3 shows the distribution of patient and spouse concordance on level of pain catastrophizing. A $\chi^{2}$ analysis revealed that although there was a trend for the low catastrophizing patient-high catastrophizing spouse group to be under-represented in the sample, the difference was not significant $\left(\chi^{2}[1, n=50]=3.10, P=0.079\right)$.

\section{Patients' pain ratings}

Patients' pain ratings were analyzed using a three-way ANOVA (level of patient catastrophizing $\times$ level of spouse catastrophizing as betweensubject factors), with canister position as the repeated measure factor. This analysis revealed a marginally significant main effect for level of patient catastrophizing $(\mathrm{F}[1,50]=3.31, \mathrm{P}=0.08)$ : high catastrophizers reported slightly more intense pain (mean $[ \pm \mathrm{SD}] 4.3 \pm 2.9$ ) than low catastrophizers (mean 3.0 \pm 2.0 ). A significant main effect for canister position also emerged $(\mathrm{F}[2,90]=32.30, \mathrm{P}<0.01)$. Tests of simple effects revealed that lifting canisters in the third row (farthest away from the body) induced significantly more pain (mean $4.5 \pm 2.7$ ) than canisters in the middle (mean 3.9 $\pm 2.6 ; \mathrm{t}[49]=4.75, \mathrm{P}<0.001$ ) or in the first row ( mean $3.1 \pm 2.3 ; \mathrm{t}[49]=7.74, \mathrm{P}<0.001)$. There were no significant interaction effects.

\section{Patients' self-reported disability and depression}

A two (high catastrophizing patient-low catastrophizing patient) by two (high catastrophizing spouse-low catastrophizing spouse) multivariate ANOVA was conducted on patients' self-reported disability and depression. This analysis revealed a significant main effect for level of patient catastrophizing $(\mathrm{F}[2,45]=18.4, \mathrm{P}<0.001)$, which was univariately significant for both self-reported disability and depression. Specifically, patients demonstrating high levels of catastrophizing reported greater disability (mean 26.4 \pm 15.2 ) than patients with low levels of catastrophizing (mean 21.5 \pm 12.6 ). In addition, patients with high levels of catastrophizing reported greater depression symptoms (mean 15.8 \pm 11.6 ) than patients with low levels of catastrophizing (mean 12.9 \pm 10.2 ). Table 4 presents the means and SDs for patients' depression and pain scores as a function of couple concordance of pain catastrophizing. 
TABLE 2

Correlations between pain-related variables and pain behaviours

\begin{tabular}{|c|c|c|c|c|c|c|c|c|c|c|c|}
\hline & MPQ-PPI & MPQ-PRI & BDI-II & PCS & TSK & PDI & P-PCS & Punitive & Solicit & Distract & Behav \\
\hline MPQ-PPI & - & & & & & & & & & & \\
\hline MPQ-PRI & $0.31^{*}$ & - & & & & & & & & & \\
\hline BDI-II & $0.32^{*}$ & $0.44^{\star *}$ & - & & & & & & & & \\
\hline TSK & 0.23 & $0.34^{\star}$ & $0.40^{* *}$ & $-0.67^{\text {** }}$ & - & & & & & & \\
\hline PDI & $0.39 * *$ & $0.30^{*}$ & $0.34^{*}$ & $0.50^{\star *}$ & $0.56^{\star \star}$ & - & & & & & \\
\hline P-PCS & 0.04 & 0.18 & 0.09 & 0.18 & $0.31^{*}$ & 0.07 & - & & & & \\
\hline Solicit & -0.11 & 0.00 & -0.03 & 0.15 & 0.20 & 0.14 & -0.06 & $-0.31^{\star}$ & - & & \\
\hline Distract & -0.19 & -0.12 & -0.04 & 0.04 & -0.09 & -0.02 & 0.20 & -0.21 & $0.41^{\star *}$ & - & \\
\hline Behav & 0.15 & 0.11 & 0.11 & $0.27^{\star *}$ & $0.31^{*}$ & $0.47^{\star *}$ & -0.19 & -0.13 & $0.34^{*}$ & 0.05 & - \\
\hline
\end{tabular}

${ }^{*} P<0.05 ;{ }^{*} P<0.01$. BDI-II Beck Depression Inventory-II; Behav Pain behaviours; Distract Distractive responses; MPQ-PPI McGill Pain Questionnaire - Present Pain Intensity; MPQ-PRI MPQ - Pain rating index; PCS Pain Catastrophizing Scale; PDI Pain Disability Index; P-PCS PCS completed by the spouse; Punitive Punitive responses; Solicit Solicitous responses; TSK Tampa Scale for Kinesiophobia

TABLE 3

Patient and spouse concordance of pain catastrophizing

\begin{tabular}{lcc}
\hline & \multicolumn{2}{c}{ Patient catastrophizing type } \\
\cline { 2 - 3 } Spouse catastrophizing type & High & Low \\
\hline High & 16 & 5 \\
Low & 15 & 14 \\
\hline
\end{tabular}

TABLE 4

Depression and pain scores as a function of couple concordance of pain catastrophizing

\begin{tabular}{lcc}
\hline & \multicolumn{2}{c}{ Patient catastrophizing type } \\
\cline { 2 - 3 } & \multicolumn{1}{c}{ High } & Low \\
\hline Patient depressive symptoms (BDI-II) & $18.88 \pm 6.86$ & $6.00 \pm 4.30$ \\
High catastrophizing spouse & $18.07 \pm 11.57$ & $7.43 \pm 4.18$ \\
Low catastrophizing spouse & & \\
Spouse depressive symptoms (BDI-II) & $15.19 \pm 10.51$ & $11.00 \pm 7.71$ \\
High catastrophizing spouse & $6.60 \pm 4.85$ & $8.00 \pm 6.76$ \\
Low catastrophizing spouse & & \\
Patient pain ratings (MPQ-PPI) & $4.75 \pm 2.08$ & $3.40 \pm 1.82$ \\
High catastrophizing spouse & $5.47 \pm 2.10$ & $3.57 \pm 2.24$ \\
Low catastrophizing spouse & & \\
Patient pain ratings during the lifting task & $4.24 \pm 2.88$ & $2.88 \pm 2.25$ \\
High catastrophizing spouse & $4.43 \pm 2.37$ & $2.99 \pm 1.95$ \\
\hline
\end{tabular}

Data presented as mean \pm SD. BDI-II Beck Depression Inventory-II; MPQ-PPI

McGill Pain Questionnaire - Present Pain Intensity

Patients' pain behaviour

A three-way ANOVA (level of participant catastrophizing $\times$ level of spouse catastrophizing as between-subject factors), with canister position as the repeated measure factor, was conducted on the total pain behaviour scores. The analysis revealed a significant main effect for level of patient catastrophizing $(\mathrm{F}[1,46]=11.16, \mathrm{P}=0.002)$. This main effect was qualified by a significant level of patient catastrophizing $\times$ level of spouse catastrophizing $(F[1,46]=4.03, P=0.05)$. Tests of simple effects revealed that high catastrophizing patients in a relationship with low catastrophizing spouses (mean 119.67 \pm 76.11 ) displayed more than twice the amount of pain behaviour than high catastrophizing patients in a relationship with high catastrophizing spouses (mean $62.88 \pm 56.25, \mathrm{P}=0.03)$. These data are presented in Figure 1.

A significant effect of canister position also emerged ( F 2,92$]=43.40$, $\mathrm{P}<0.001)$ : patients displayed significantly more pain behaviours while lifting canisters in the third row (mean 26.8 \pm 26.3 ) compared with the

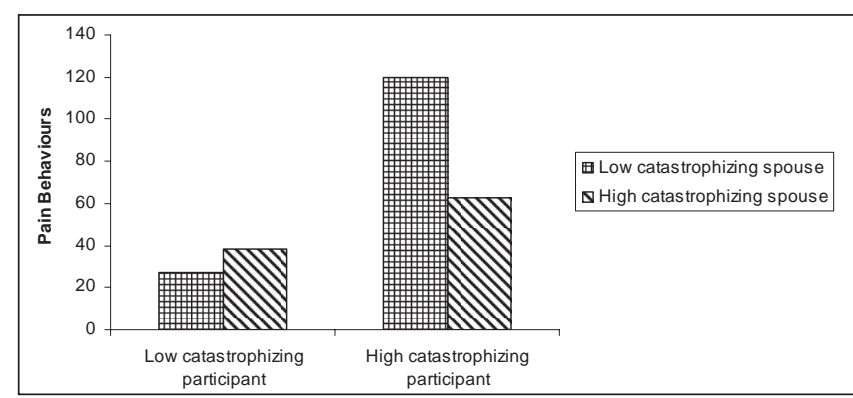

Figure 1) Pain behaviour level for the different couple concordances of pain catastrophizing

second (mean 14.0 $\pm 19.6 ; \mathrm{t}[49]=-4.85, \mathrm{P}<0.001$ ) or the first row (mean $13.3 \pm 19.2 ; \mathrm{t}[49]=-5.10, \mathrm{P}<0.001)$.

It is possible that the high catastrophizing patients in a relationship with low catastrophizing spouses expressed more pain behaviours as a result of more intense pain, more severe depression or more disability (9,41-46). A hierarchical regression was, therefore, conducted to examine the relative contribution of pain intensity, depression and selfreported disability to group differences in pain behaviour between high catastrophizing participants with high or low catastrophizing spouses. As shown in Table 5, pain, depression and self-reported disability were entered in step 1 of the analysis. Group type (high catastrophizing patient-high catastrophizing spouse versus high catastrophizing patientlow catastrophizing spouse) was entered in step 2 of the analysis, and contributed significant variance to the prediction of the total amount of pain behaviours. Group type accounted for $22 \%$ of the variance in pain behaviours, beyond the variance accounted for by pain intensity, depression and self-reported disability. Examination of the beta weights indicated that, in the final regression equation, self-reported disability and Group type contributed unique variance to the prediction of the total amount of pain behaviours.

\section{Spouse's pain estimates}

Spouses' pain estimates were analyzed using a three-way ANOVA (level of patient catastrophizing $\times$ level of spouse catastrophizing as betweensubject factors), with canister position as the repeated measures factor. A significant main effect for level of patient catastrophizing emerged $(\mathrm{F}[1,49]=6.64, \mathrm{P}=0.01)$, as well as a marginally significant main effect for level of spouse catastrophizing $(F[1,49]=3.80, P=0.06)$. Spouses of high catastrophizing patients perceived more pain (mean 4.0 \pm 2.3 ) than spouses of low catastrophizing patients (mean $2.3 \pm 1.4$ ). High catastrophizing spouses perceived significantly more pain (mean $4.3 \pm 2.5$ ) than low catastrophizing spouses (mean 2.6 \pm 1.6 ). 
TABLE 5

Regression analysis examining predicting pain behaviours

\begin{tabular}{|c|c|c|c|c|c|c|}
\hline Step & Variable & $\mathbf{R}^{2}$ & $R^{2}$ change & F change & Standardized beta & $t$ \\
\hline \multirow[t]{2}{*}{1} & Pain (McGill Pain Questionnaire - Present Pain Intensity) & 0.20 & 0.20 & 2.21 & -0.12 & -0.75 \\
\hline & Participant disability (Pain Disability Index) & & & & 0.47 & $2.99^{* *}$ \\
\hline
\end{tabular}

*Significant at the 0.05 level; **Significant at the 0.01 level

Consistent with previous research using this paradigm (12), canister position also emerged as a significant contributor of spouse's pain estimates $(\mathrm{F}[2,90]=37.9, \mathrm{P}<0.001)$. Tests of simple effects revealed that spouses perceived more pain when their partner lifted canisters in the third row (mean 4.2 \pm 2.5 ) compared with the second (mean 3.5 \pm 2.2 ; $\mathrm{t}[48]=4.25, \mathrm{P}<0.001)$ or first row $($ mean $2.4 \pm 2.1 ; \mathrm{t}[48]=8.74, \mathrm{P}<0.001)$.

\section{Spouses' reinforcing and punishing responses}

A two-way ANOVA (level of patient catastrophizing $\times$ level of spouse catastrophizing) was conducted on patients' perception of solicitous response from the spouse. No main or interaction effect emerged.

A two-way ANOVA (level of patient catastrophizing $\times$ level of spouse catastrophizing) was conducted on patients' perception of punishing response from the spouse. The analysis revealed a marginally significant main effect for level of patient catastrophizing $(\mathrm{F}[1,45]=3.19, \mathrm{P}=0.08)$, where high catastrophizers reported slightly more punishing responses (mean 1.9 \pm 1.3 ) than low catastrophizers (mean 1.6 \pm 1.2 ). This effect was qualified by a marginally significant interaction $(F[1,45]=3.36, P=0.08)$, revealing a trend for patients to perceive more punishing responses from their spouses when both partners were high catastrophizers.

A hierarchical regression was performed to examine the relative contribution of high catastrophizing patients' perception of punishing responses from their spouses in the prediction of pain behaviours. As shown in Table 6, spouse catastrophizing was entered in step 1 of the analysis. In step 2, the perceived punishing response was entered. Pain, depression and self-reported disability were entered in step 3. Group type and self-reported disability contributed unique variance to the prediction of the total amount of pain behaviours. Specifically, group type accounted for $15 \%$ of the variance and self-reported disability accounted for $20 \%$ of the variance.

\section{DISCUSSION}

The primary aim of the present study was to assess the relationship between couple concordance of catastrophizing and adverse pain outcomes. Consistent with previous research, high scores on the PCS (for pain patients) were associated with more intense pain (7-10), more severe depression and more pronounced disability (47-49).

It was also found that high catastrophizing spouses perceived significantly more pain. This finding is consistent with previous research showing that catastrophizers are more sensitive to pain cues of other people (11). Similarly, independent of their own catastrophizing levels, spouses of high catastrophizing patients perceived slightly more pain in their partners. This result is consistent with previous research suggesting that catastrophizers may be more effective communicators of their pain experience (8).

Of central interest in the present study were the interactive or summative effects of participants' and their spouses' levels of catastrophizing on patients' pain outcomes. Results indicated that spouse level of catastrophizing interacted with patient level of catastrophizing only for the display of pain behaviour. Specifically, high catastrophizing patients who were in a relationship with a low catastrophizing spouse displayed the greatest amount of pain behaviour. A hierarchical regression revealed that couple concordance of catastrophizing accounted for $22 \%$ of the variance in pain behaviour scores, beyond the variance accounted for by pain intensity, depression and self-reported disability.

Proceeding from a cognitive-behavioural perspective, the highest levels of pain behaviour might have been expected in couples for
TABLE 6 Regression analysis examining predictors of pain behaviours among high catastrophizing patients

\begin{tabular}{|c|c|c|c|c|c|}
\hline Step and variable & $\mathbf{R}^{2}$ & $\begin{array}{c}\mathrm{R}^{2} \\
\text { change }\end{array}$ & $\begin{array}{c}F \\
\text { change }\end{array}$ & $\begin{array}{c}\text { Standardized } \\
\text { beta }\end{array}$ & $T$ \\
\hline Step 1 & 0.15 & 0.15 & $4.94^{*}$ & & \\
\hline Spouse catastrophizing & & & & 0.42 & $2.61^{\star *}$ \\
\hline Step 2 & 0.22 & 0.08 & 2.69 & & \\
\hline Punishing responses (MPI) & & & & -0.21 & -1.26 \\
\hline Step 3 & 0.45 & 0.23 & 3.50 & & \\
\hline Pain (MPQ-PPI) & & & & -0.18 & -0.11 \\
\hline $\begin{array}{l}\text { Patient depressive } \\
\text { symptoms (BDI-II) }\end{array}$ & & & & -0.13 & -0.87 \\
\hline Patient disability (PDI) & & & & 0.48 & 3.02 \\
\hline
\end{tabular}

${ }^{*}$ Correlation is significant at the 0.05 level; ${ }^{* *}$ Correlation is significant at the 0.01 level. BDI-II Beck Depression Inventory-II; MPI Multidimensional Pain Inventory; MPQ-PPI McGill Pain Questionnaire - Present Pain Intensity; PDI Pain Disability Index

whom both partners were high catastrophizers. In other words, a summative effect of the heightened threat appraisals of both members of the catastrophizing couple would have contributed to more intense emotional distress and pain and, in turn, to more pain behaviour.

Cano et al (1) reported finding an interaction between patient and spouse catastrophizing and emotional distress. When both spouses were high catastrophizers, the pain patients reported significantly more depressive symptoms than high catastrophizers who were in relationships with low catastrophizers (1). Cano et al interpreted their findings by suggesting that pain catastrophizing in both spouses could result in specific behaviours (ie, a worried pain participant in a relationship with a solicitous spouse, in which both partners are focused on the pain problem) that may exacerbate depressive symptoms experienced by the pain participant. The results of the present study do not replicate this effect. It is possible that cross-sample differences in measurement instruments, sample composition or chronicity might have accounted for the discrepancy in findings. It is important to note that in the Cano et al (1) study, spouses' catastrophizing about their partner's pain was assessed. In the present study, spouses' catastrophizing about their own pain was assessed.

The findings of the present study support a communication perspective of pain catastrophizing. It is possible that the high catastrophizing chronic pain patient might need to increase the 'volume' of pain communication to compensate for the low catastrophizing spouses' tendency to underestimate pain signals. In communication studies, researchers have proposed a hierarchy hypothesis that suggests that when individuals believe that their communication goals are not achieved, they will choose the least cognitively demanding option to increase the communication impact such as repetition, increased vocal amplitude or reduced speech rate $(50,51)$.

Operant explanations have previously been invoked to account for heightened expressions of pain behaviour $(46,52)$. In previous research, significant relationships were reported between spouse solicitousness and patient pain behaviour (52-55). Similar findings were obtained in the present study. It could be suggested that pain behaviour might be reinforced by solicitous behaviours from the spouse (eg, expressions of 
concern, support and provision of assistance) in couples for whom the high catastrophizing pain patient is in a relationship with a low catastrophizing spouse (52-54). However, the lack of a significant relationship between couple concordance of catastrophizing and the patients' perception of their spouses' solicitousness does not support a reinforcement hypothesis.

It is also possible that in couples for whom both partners are high catastrophizers, the spouse may develop a punitive style of behaviour (ie, responding with irritation, frustration, anger and ignorance) in reaction to pain behaviours $(56,57)$, which would explain the lower levels of pain behaviour in these couples. The present findings indicate that in couples in whom both partners were high catastrophizers, there was a marginally significant interaction effect between couple concordance of pain catastrophizing and patients' perception of punitive responses from the spouse. Examination of means showed that the pain patient perceived more punitive responses from the spouse. However, when a regression analysis was performed to test the predictors of pain behaviours, couple concordance of catastrophizing remained significant even when controlling for the contribution of participant's perceived punitive responses from the spouse. This result suggests that the higher level of patients' perception of punitive responses from the spouse does not explain the lower rates of pain behaviours found in the couples for whom both partners were high catastrophizers.

It is noteworthy that spouse level of catastrophizing did not moderate the relationship between patient level of catastrophizing and pain severity, depression or self-reported disability. Differences in the manner in which these variables are assessed might account, at least in part, for this pattern of findings. Pain behaviour was the only overt variable assessed in the study. Overt behaviours are more likely to be influenced by contextual variables because they are perceived and responded to by others. Self-reports of internal experience (ie, pain or depression) or limitations (ie, disability) might not fall under control of environmental contingencies in the same manner as overt behaviour. Although respondents provide numerical values to describe their pain and distress, individuals typically do not use numerical values to communicate their experience in day-to-day interactions.

The distribution of concordance pairings of pain catastrophizing showed a trend toward under-representation of couples in whom the pain patient is a low catastrophizer and the spouse is a high catastrophizer. Assortative mating theory suggests that individuals are more likely to marry people who share similar characteristics such as demographics, attitudes, behaviours and coping strategies $(58,59)$. However, high catastrophizing patients with a low catastrophizing spouse were represented with the same frequency as concordant couples. It is possible that the low catastrophizing patient might be less attracted to someone who displays a catastrophic orientation to health threats, or that spouses' level of catastrophizing might diminish after a period of living with a low catastrophizer. It is also important to consider that partners would have likely met before the onset of a pain condition, and levels of catastrophizing might change following the onset of pain. As such, the current distribution of concordance pairings may not be representative of couples' pre-pain relationships.

The present study's findings have several clinical implications. First, the findings highlight the importance of being receptive to clients' pain communications. In the past, behavioural models of pain behaviour advocated ignoring patients' displays of pain (60). These recommendations were based on the opinion that pain behaviours were reinforced by attention, and could be extinguished through systematic nonreinforcement. However, the present findings suggest that, at least for high catastrophizers, ignoring pain behaviours might lead to an increase in pain behaviour. To the extent that pain behaviour contributes to disability, ignoring patients' pain behaviour might inadvertently increase disability as well (61). A recent study of communication between pain patients and their spouses (62) showed that validation by both partners was positively correlated with marital satisfaction and perceived spousal support. Active listening leads to mutual understanding, which in turn, reduces the patient's need to express verbal or nonverbal messages of distress (63) such as pain behaviours. Interventions aimed at improving the communication skills (active listening) of the partners should be considered, specifically for couples in whom the patient is a high catastrophizer and the spouse is a low catastrophizer (64).

A certain degree of caution needs to be exercised in the interpretation of the present findings. First, because the participants were recruited through newspaper advertisements, the sample may not be representative of the patients attending pain treatment centres. In addition, the modest sample size limits the nature of the relationships that could be explored, and permits elucidation of only relationships associated with moderate or large effect sizes. Pain behaviour was also assessed under standardized laboratory conditions, with the partner in a separate room, who only saw the video without sound. While such conditions are important from the perspective of scientific rigor, they also strain the ecological validity of the findings.

In spite of these limitations, the present study is the first to demonstrate that concordance of pain catastrophizing in couples, where one partner suffers from persistent pain, influences the display of pain behaviour. More research is needed to identify the mechanisms that underlie this interaction.

ACKNOWLEDGEMENTS: This research was supported by grants from the Canadian Institutes of Health Research, and the Social Sciences and Humanities Research Council of Canada.

DISCLOSURE: Portions of this research were presented at the Annual Meeting of the Canadian Pain Society, Ottawa, Ontario, 2007.

\section{REFERENCES}

1. Cano A, Leonard MT, Franz A. The significant other version of the Pain Catastrophizing Scale (PCS-S): Preliminary validation. Pain 2005;119:26-37.

2. Leonard MT, Cano A. Pain affects spouses too: Personal experience with pain and catastrophizing as correlates of spouse distress. Pain 2006;126:139-46.

3. Sullivan MJL, Thorn B, Haythornthwaite JA, et al.

Theoretical perspectives on the relation between catastrophizing and pain. Clin J Pain 2001;17:52-64.

4. Sullivan MJL, Tripp DA, Santor D. Gender differences in pain and pain behavior: The role of catastrophizing. Cognit Ther Res 2000;24:121-34.

5. Craig KD. The social communication model of pain. Can Psychol 2009;50:22-32

6. Hadjistavropoulos T, Craig KD. A theoretical framework for understanding self-report and observational measures of pain: A communications model. Behav Res Ther 2002;40:551-70.

7. Sullivan MJL. Toward a biopsychomotor conceptualization of pain: Implications for research and intervention. Clin J Pain 2008;24:281-90.

8. Sullivan MJL, Martel MO, Tripp D, Savard A, Crombez G. The relation between catastrophizing and the communication of pain experience. Pain 2006;122:282-8.

9. Thibault P, Loisel P, Durand MJ, Catchlove R, Sullivan MJ. Psychological predictors of pain expression and activity intolerance in chronic pain patients. Pain 2008;139:47-54.

10. Vervoort T, Craig K, Goubert L, et al. Expressive dimensions of pain catastrophizing: A comparative analysis of school children and children with clinical pain. Pain 2008;134:59-68.

11. Sullivan MJL, Martel MO, Tripp DA, Savard A, Crombez G. Catastrophic thinking and heightened perception of pain in others. Pain 2006;123:37-44.

12. Martel MO, Thibault P, Roy C, Catchlove R, Sullivan MJL. Contextual determinants of pain judgments. Pain 2008;139:562-8.

13. Leeuw M, Goossens MEJB, van Breukelen GJP, et al. Exposure in vivo versus operant graded activity in chronic low back pain patients: Results of a randomized controlled trial. Pain 2008;138:192-207.

14. Severeijns R, Vlaeyen JW, van den Hout MA, Picavet H. Pain catastrophizing is associated with health indices in musculoskeletal pain: A cross-sectional study in the Dutch community. Health Psychol 2004;23:49-57. 
15. Turner JA, Aaron LA. Pain-related catastrophizing: What is it? Clin J Pain 2001;17:65-71.

16. Vlaeyen JW, Linton SJ. Fear-avoidance and its consequences in chronic musculoskeletal pain: A state of the art. Pain 2000;85:317-32.

17. Melzack R. The McGill Pain Questionnaire: Major properties and scoring methods. Pain 1975;1:277-99.

18. Veilleux S, Sicard D, Bohuon A. Divers types de douleur. In: Melzack R, Wall PD, eds. Le défi de la douleur: Troisième édition entièrement refondue. St-Hyacinthe: Edisem, 1989:31-9.

19. Beck AT, Steer RA, Brown GK. Manual for Beck Depression Inventory II (BDI-II). San Antonio: Psychology Corporation, 1996.

20. Gauthier N, Thibault P, Adams H, Sullivan MJ. Validation of a French-Canadian version of the Pain Disability Index. Pain Res Manag 2008;13:327-33.

21. Tait RC, Pollard CA, Margolis RB, Duckro PN, Krause SJ The Pain Disability Index: Psychometric and validity data. Arch Phys Med Rehabil 1987;68:438-41.

22. French DJ, Noel M, Vigneau F, French JA, Cyr CP, Evans RT. PCS-CF: A French-language, French-Canadian adaptation of the Pain Catastrophizing Scale. Can J Behav Sci 2005;37:181-92.

23. Sullivan MJL, Bishop SR, Pivik J. The Pain Catastrophizing Scale: Development and validation. Psychol Assess 1995;7:524-32.

24. Kerns RD, Turk DC, Rudy TE. The West Haven-Yale Multidimensional Pain Inventory (WHYMPI). Pain 1985;23:345-56.

25. Laliberte S, Lamoureux J, Sullivan MJL, Miller J-M, Charron J, Bouthillier D. French translation of the Multidimensional Pain Inventory: L'inventaire multidimensionnel de la douleur. Pain Res Manag 2008;13:497-505.

26. Butler HL, Kozey JW. The effect of load and posture on load estimations during a simulated lifting task in female workers. Int J Ind Ergon 2003:31:331-41.

27. Karwowski W, Shumate C, Yates J, Pongpatana N. Discriminability of load heaviness: Implications for the psychophysical approach to manual lifting. Ergonomics 1992;35:729-44.

28. Waters TR, Putz-Anderson V, Garg A, Fine L. Revised NIOSH equation for the design and evaluation of manual lifting tasks. Ergonomics 1993;36:749-76.

29. Osman A, Barrios FX, Gutierrez PM, Kopper BA, Merrifield T, Grittmann L. The Pain Catastrophizing Scale: Further psychometric evaluation with adult samples. J Behav Med 2000;23:351-65.

30. Van Damme S, Crombez G, Bijttebier P, Goubert L, Van Houdenhove B. A confirmatory factor analysis of the Pain Catastrophizing Scale: Invariant factor structure across clinical and non-clinical populations. Pain 2002;96:319-24.

31. Turk DC, Rudy TE, Salovey P. The McGill Pain Questionnaire reconsidered: Confirming the factor structure and examining appropriate uses. Pain 1985;21:385-97.

32. Arnau RC, Meagher MW, Norris MP, Bramson R. Psychometric evaluation of the Beck Depression Inventory-II with primary care medical patients. Health Psychol 2001;20:112-9.

33. Bishop SR, Edgley K, Fisher R, Sullivan MJL. Screening for depression in chronic low back pain with the Beck Depression Inventory. Can J Rehabil 1993;7:143-8.

34. Vowles KE, Gross RT, Sorrell JT. Predicting work status following interdisciplinary treatment for chronic pain. Eur J Pain 2004;8:351-8

35. Pollard CA. Preliminary validity study of the pain disability index. Percept Mot Skills 1984;59:974.

36. Tait RC, Chibnall JT, Krause S. The Pain Disability Index: Psychometric properties. Pain 1990;40:171-82.

37. Sullivan MJL, Thibault P, Savard A, Catchlove R, Kozey J, Stanish WD. The influence of communication goals and physical demands on different dimensions of pain behavior. Pain 2006;125:270-7.

38. Prkachin KM, Schultz I, Berkowitz J, Hughes E, Hunt D. Assessing pain behavior of low-back pain patients in real time: Concurrent validity and examiner sensitivity. Behav Res Ther 2002:40:595-607.

39. Tabachnick BG, Fidell LS. Using multivariate statistics. Boston: Pearson/Allyn \& Bacon, 2007.
40. Sullivan MJL, Adams H, Thibault P, Corbiere M, Stanish WD. Initial depression severity and the trajectory of recovery following cognitive-behavioural intervention for work disability. J Occup Rehabil 2006;16:60-71.

41. Dickens C, Jayson M, Creed F. Psychological correlates of pain behavior in patients with chronic low back pain. Psychosomatics 2002;43:42-8.

42. Keefe FJ, Wilkins RH, Cook WA Jr, Crisson JE, Muhlbaier LH. Depression, pain, and pain behaviour. J Consult Clin Psychol 1986;54:665-9.

43. Krause SJ, Wiener RL, Tait RC. Depression and pain behavior in patients with chronic pain. Clin J Pain 1994;10:122-7.

44. McCahon S, Strong J, Sharry R, Cramond T. Self-report and pain behavior among patients with chronic pain. Clin J Pain 2005;21:223-31.

45. Pence LB, Thorn BE, Jensen MP, Romano JM. Examination of perceived spouse responses to patient well and pain behavior in patients with headache. Clin J Pain 2008;24:654-61.

46. Prkachin KM, Schultz IZ, Hughes E. Pain behavior and the development of pain-related disability: The importance of guarding. Clin J Pain 2007;23:270-7.

47. Sullivan MJL, Stanish W, Waite H, Sullivan M, Tripp DA. Catastrophizing, pain, and disability in patient with soft-tissue injuries. Pain 1998;77:253-60.

48. Swinkels-Meewisse IE, Roelofs J, Oostendorp RA, Verbeek AL, Vlaeyen JW. Acute low back pain: Pain-related fear and pain catastrophizing influence physical performance and perceived disability. Pain 2006;120:36-43.

49. Turner JA, Jensen MP, Warms CA, Cardenas DD. Catastrophizing is associated with pain intensity, psychological distress, and pain-related disability among individuals with chronic pain after spinal cord injury. Pain 2002;98:127-34.

50. Berger CR, DiBattista P. Communication failure and plan adaptation: If at first you don't succeed, say it louder and slower. Commun Monogr 1993;60:220-38

51. Cai DA, Rodríguez JI. Adjusting to cultural differences: The Intercultural Adaptation Model. Intercultural Communication Studies 1996-7;VI:31-42.

52. Romano JM, Turner JA, Friedman LS, et al. Sequential analysis of chronic pain behaviors and spouse responses. J Consult Clin Psychol 1992;60:777-82.

53. Paulsen JS, Altmaier EM. The effects of perceived versus enacted social support on the discriminative cue function of spouses for pain behaviors. Pain 1995;60:103-10.

54. Romano JM, Turner JA, Jensen MP, et al. Chronic pain patient-spouse behavioral interactions predict patient disability. Pain 1995;63:353-60.

55. Newton-John TRO. Solicitousness and chronic pain: A critical review. Pain Reviews 2002;9:7-27.

56. Boothby JL, Thorn BE, Overduin LY, Ward LC. Catastrophizing and perceived partner responses to pain. Pain 2004;109:500-6.

57. Waxman SE, Tripp DA, Flamenbaum R. The mediating role of depression and negative partner responses in chronic low back pain and relationship satisfaction. J Pain 2008;9:434-42.

58. Ptacek J, Dodge KL. Coping strategies and relationship satisfaction in couples. Pers Soc Psychol Bull 1995;21:76-84.

59. Rhule-Louie DM, McMahon RJ. Problem behavior and romantic relationships: Assortative mating, behavior contagion, and desistance. Clin Child Fam Psychol Rev 2007;10:53-100.

60. Fordyce WE. Behavioral methods for chronic pain and illness. Saint Louis: Mosby, 1976.

61. Prkachin KM, Solomon PE, Ross J. Underestimation of pain by health-care providers: Towards a model of the process of inferring pain in others. Can J Nurs Res 2007;39:88-106.

62. Cano A, Barterian JA, Heller JB. Empathic and nonempathic interaction in chronic pain couples. Clin J Pain 2008;24:678-84.

63. Lang F, Floyd MR, Beine KL. Clues to patients' explanations and concerns about their illnesses. A call for active listening. Arch Fam Med 2000;9:222-7.

64. Thorn B, Ward L, Sullivan M, Boothby J. Communal coping model of catastrophizing: Conceptual model building. Pain 2003;106:1-2. 


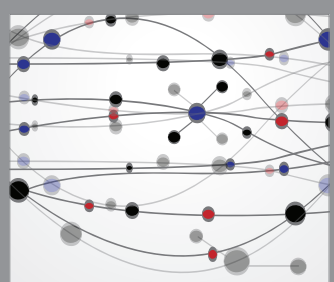

The Scientific World Journal
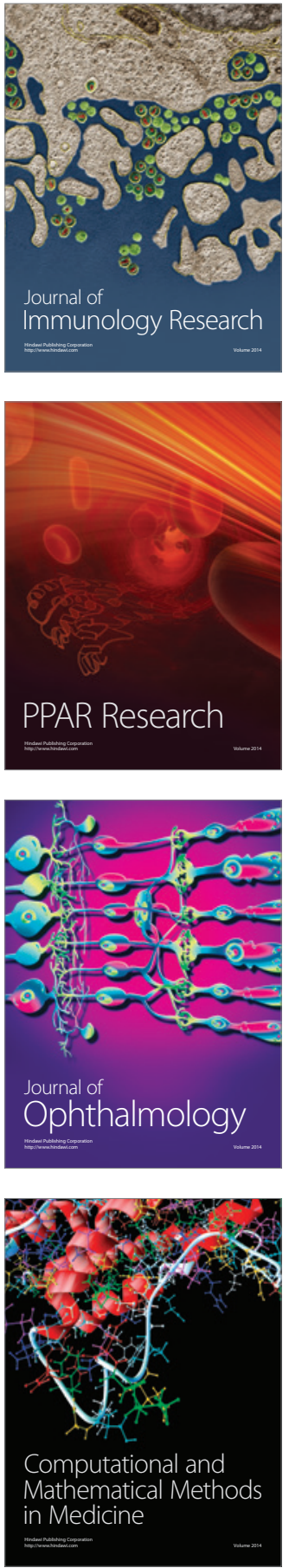

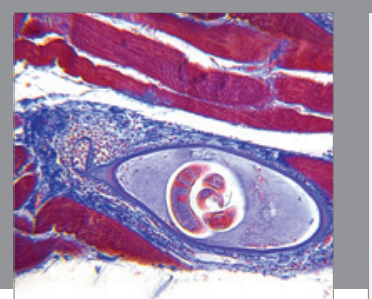

Gastroenterology Research and Practice

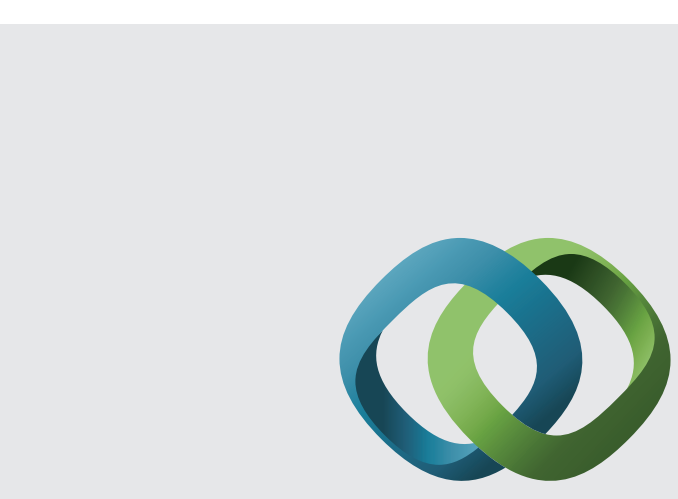

\section{Hindawi}

Submit your manuscripts at

http://www.hindawi.com
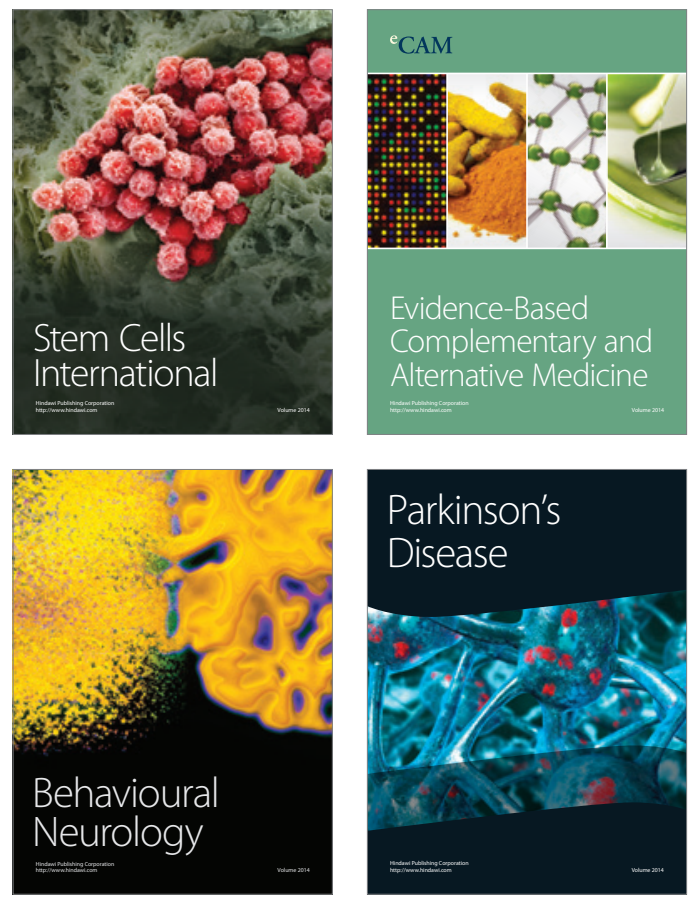
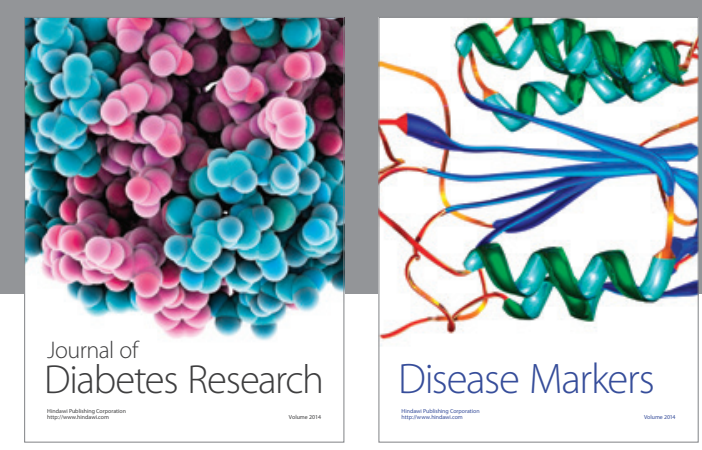

Disease Markers
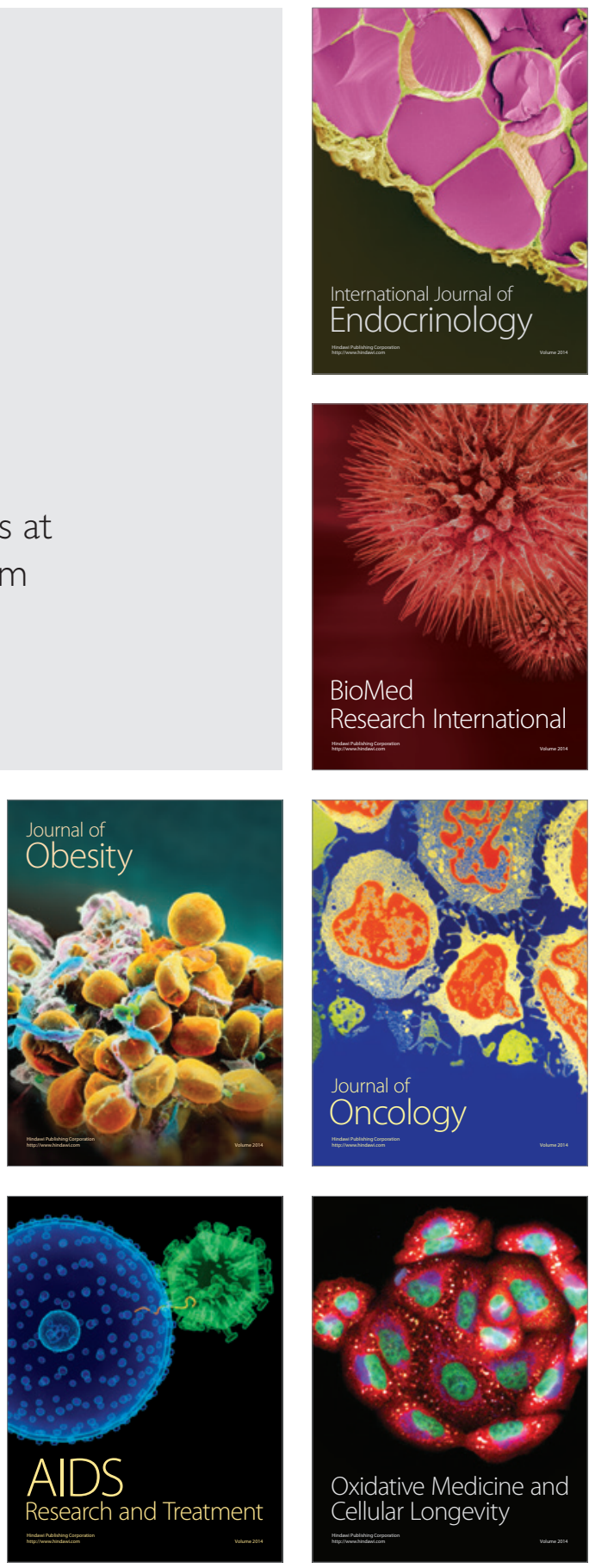